\title{
Patterns of psychotherapy development: A mixed- method analysis using assimilation indices
}

\section{David Dias Neto, Telmo Mourinho Baptista \& Kim Dent-Brown}

To cite this article: David Dias Neto, Telmo Mourinho Baptista \& Kim Dent-Brown (2015) Patterns of psychotherapy development: A mixed-method analysis using assimilation indices, Counselling Psychology Quarterly, 28:1, 78-96, DOI: 10.1080/09515070.2014.926860

To link to this article: https://doi.org/10.1080/09515070.2014.926860

\section{Published online: 19 Jun 2014.}

\section{[4 Submit your article to this journal $\sqsubset$}

\section{山 Article views: 118}

Q View related articles $₫$

View Crossmark data $₫$

4

Citing articles: 1 View citing articles $₫$ 


\title{
Patterns of psychotherapy development: A mixed-method analysis using assimilation indices
}

\author{
David Dias Neto $^{\mathrm{a}, \mathrm{b} *}$, Telmo Mourinho Baptista ${ }^{\mathrm{a}}$ and Kim Dent-Brown ${ }^{\mathrm{b}}$ \\ ${ }^{a}$ Faculdade de Psicologia, Universidade de Lisboa, Lisboa, Portugal; ${ }^{b}$ School of Health and \\ Related Research, University of Sheffield, Sheffield, UK
}

(Received 29 September 2013; accepted 18 May 2014)

\begin{abstract}
Understanding how assimilation develops is essential in promoting personal change. By attending to signs or indices of assimilation in the speech of clients, therapists can use this process to assess how the therapy is developing and to tailor intervention. The system of assimilation indices was developed to use assimilation to understand the process of change. This system signals five sub-processes of assimilation: external distress, pain, noticing, decentring, and action. This study consisted of a longitudinal mixed-method analysis, following a multiple cases embedded design. The system of assimilation indices was applied to the recordings of nine psychotherapies and contrasted with both the outcome of the therapy and the perspectives of the therapists and clients about their therapy process. The results show that the system of indices is useful in understanding multiple pathways for assimilation. The system of indices is seen as a useful tool for understanding assimilation and as having clinical value in anticipating challenges to the success of the therapy. This study also shows how the indices are sensitive to the nuances in the change process observed in clinical settings.
\end{abstract}

Keywords: assimilation; process research; indices; change processes

\section{Introduction}

One process that is considered to be central in understanding human psychological change is assimilation. Etymologically, assimilation comes from the Latin assimilāre, which means "to make similar." This definition is similar to the first formulation of assimilation in psychology (e.g. Piaget \& Inhelder, 1969). In this early formulation, assimilation was viewed as the modification of the representations of an event in the process of integrating it into a pre-existing structure or schema. Eventually, this preexisting structure would be modified to integrate new and incompatible information.

Stiles and collaborators realized that assimilation could enhance our understanding of psychotherapy and developed the Assimilation of Problematic Experiences Sequence (APES; e.g. Stiles, 2001; Stiles et al., 1990). The APES follows a community of voices approach to identity. In this perspective, significant experiences can leave traces that can constitute voices or stances of identity (e.g. Honos-Webb, Stiles, Greenberg, \& Goldman, 1998). Problematic experiences correspond to painful or incongruent experiences that are avoided or suppressed and constitute non-dominant voices. Assimilation

\footnotetext{
*Corresponding author. Email: d.neto@campus.ul.pt
} 
is the process of integrating these voices in the community of voices. According to this perspective, problematic experiences are assimilated through a series of stages that range from warded off to integration.

Research on assimilation in psychotherapy follows primarily this model, and a number of qualitative single-case studies have been used to support and theoretically extend it (e.g. Honos-Webb, Stiles, et al., 1998; Honos-Webb, Surko, Stiles, \& Greenberg, 1999; Osatuke et al., 2005). The model has also been supported by a number of studies that quantitatively related assimilation to process and outcome measures of psychotherapy (e.g. Detert, Llewelyn, Hardy, Barkham, \& Stiles, 2006; Gabalda, 2005; Rudkin, Llewelyn, Hardy, Stiles, \& Barkham, 2007).

Since assimilation involves changes in meaning, it may be traceable in the speech of clients. The understanding of these signs is both a useful way to understand the processes and represents a tool for practitioners. The idea of trying to use signs in the speech of clients is not new and therapists attend to them intuitively. A number of examples can be found in the research in this area, namely in: the identification of markers of emotional processes (e.g. Greenberg, 2002), and linguistic indicators of particular types of narratives or groups (e.g. Neto \& Baptista, 2010; Pennebaker, Mehl, \& Niederhoffer, 2003). These examples also show the different ways in which these signs can be derived. Greenberg (2002) starts from a conceptualization of how change occurs and the processes involved and identifies markers of that process; while Pennebaker and collaborators (e.g. Pennebaker et al., 2003) start by empirically identifying differences in the use of low-level words (e.g. pronouns, prepositions, and articles) in different groups. These examples show how microelements can be used to understand the macro process of change. Furthermore, they can be used both as a process assessment tool and as indicators to tailor intervention. These elements can be called indices and are verbal and non-verbal elements in the speech that are found to be related to psychological processes.

Given the usefulness of indices or markers of psychological processes in practice contexts, we sought to identify indices of assimilation. An attempt has been made to identify markers of assimilation (Honos-Webb, Surko, \& Stiles, 1998), but this approach tended to produce low inter-rater agreement (Detert et al., 2006; Rudkin et al., 2007). This result may be due to the interpretative character of these markers that arises from their conceptual association with the assimilation model. For example, the marker of "fear of losing control" (Honos-Webb, Lani, \& Stiles, 1999) is defined as follows: explicit recognition of fear while discussing or exploring a topic; and the expectation that the "voice" will be disruptive for everyday life or previous beliefs. The identification of this voice implies a formulation of voices (i.e. dominant and non-dominant voices) for a particular case and its application to a particular excerpt to identify discrete markers. Such interpretative procedures may lead to disagreement between raters.

Additionally, the APES implies a stage view of assimilation, meaning that its indices relate assimilation in a macro and not micro level (Neto, Baptista, \& Dent-Brown, 2011). The levels of the APES, even when applied to particular excerpts, imply the understanding of where the client is in the process of psychotherapy. The present approach was an attempt to be an alternative to this coding system. We sought to develop a system of indices that was less dependent on theory and more dependent on observation. The term indices is used instead of makers to denote this difference. In this manner, the indices refer to particular utterances and the variation in their frequency of 
occurrence is continuous throughout therapy. This goal was achieved by integrating qualitative and quantitative methods.

The system of assimilation indices was created as a process measure of assimilation that sought to be less dependent on theory, thus making it more suitable for therapists. This was achieved through the qualitative analysis of psychotherapy sessions (Neto, 2011). Using Grounded Theory (Strauss \& Corbin, 1998) as the framework for analysis, the indices emerged from session recordings and not from a previous theory. The analysis was converted into a manual that is available upon request from the first author. In the system of indices, unlike other coding systems, the indices have an emergent character and will be absent in most utterances. This means that not all the material is coded and that the indices have a discrete character.

The indices are grouped in dimensions which are considered to represent sub-processes of assimilation. Therefore, the formulation of assimilation, of the system of indices, corresponds to the sub-processes represented by the dimensions. These subprocesses are considered to have different importance along the process of change. Dimensions such as "external distress" should be more represented in the beginning of the change process, while dimensions like "action" should be more likely relevant later on. The dimensions of the indices and examples are presented in Table 1.

The system of indices was applied to a cross-sectional analysis of psychotherapy sessions. Two raters independently applied the system of indices to 30 therapy sessions. The dimensions have shown acceptable inter-rater reliability and internal consistency (Neto, 2011). The combination of qualitative and quantitative procedures allowed for a system of indices that sought to reflect a deeper understanding of assimilation while meeting quantitative psychometric standards. This resulted in a useful and rigorous tool for understanding assimilation in process research.

\section{The present study}

The development of the indices (Neto, 2011) relied on a cross-sectional examination of the properties of the indices. Given the promising results of the system of indices and considering that assimilation is a developmental process, the present study was devised to analyze assimilation longitudinally. The goal of this research was to observe patterns of assimilation throughout therapy and to relate them with outcome. We expected to find two characteristics in the evolution of the dimensions of assimilation. First, in successful cases, we expected linear trends along the course of therapy. Second, we expected that the dimensions judged to correspond to early dimensions of assimilation - external and pain - decreased relative to later dimensions. Finally, we expected that later dimensions - noticing, decentring, and action -increased over the course of successful therapy.

Matching assimilation with outcome allows validating the system of assimilation indices. Cases in which there is a match are considered exemplifying cases (Bryman, 2004) that can be used to show the significance of the system in particular cases. Cases in which the development of assimilation does not match the outcome are critical cases (Bryman, 2004) in the sense that they question the theory. These cases should be analyzed further to observe whether the system is not describing change or whether change in these cases is not linear. 
Table 1. Examples of indices of each dimension of assimilation.

\begin{tabular}{|c|c|}
\hline Dimensions & Examples of indices \\
\hline $\begin{array}{l}\text { External distress. This process involves absence of elaboration, } \\
\text { avoidance, or a de-regulated emotional experience. Often, this } \\
\text { distress can be supported by external meanings or theories }\end{array}$ & $\begin{array}{l}\text { - Past as cause } \\
\text { - Laugher not congruent } \\
\text { with what is said }\end{array}$ \\
\hline $\begin{array}{l}\text { Pain. Pain represents suffering that is lived as an experience. It } \\
\text { can be either egodystonic and reflect the criticism of emotion } \\
\text { or egosyntonic and reflect impotence that can be the product } \\
\text { of an inability to elaborate }\end{array}$ & $\begin{array}{l}\text { - Confusion } \\
\text { - Indifference/resignation } \\
\text { - Incapacity to assign } \\
\text { meaning }\end{array}$ \\
\hline $\begin{array}{l}\text { Noticing. It is the process of paying attention and experiencing } \\
\text { new elements. Noticing is frequently associated with } \\
\text { strangeness with elements that are not yet integrated }\end{array}$ & $\begin{array}{l}\text { - Detailing emotional } \\
\text { experience } \\
\text { - Surprise with reaction }\end{array}$ \\
\hline $\begin{array}{l}\text { Decentring. Decentring involves the ability to elaborate a } \\
\text { meaning or an explanation that is new. It can be the } \\
\text { articulation of ambivalence due to the consideration of a } \\
\text { different perspective or a sketch of an elaboration }\end{array}$ & $\begin{array}{l}\text { - Emotional ambivalence } \\
\text { - Irony } \\
\text { - Sketch of underlying } \\
\text { meaning }\end{array}$ \\
\hline $\begin{array}{l}\text { Action. Corresponds to an elaboration of an action or a } \\
\text { reflection about change. This change may have already } \\
\text { occurred or it can be a targeted action }\end{array}$ & $\begin{array}{l}\text { - Identity change } \\
\text { - Idea of training }\end{array}$ \\
\hline
\end{tabular}

The system of assimilation indices should be able to signal psychotherapy change and its impact in outcome, but it should also be sensitive to the complexities of assimilation development. Longitudinal application of the system of indices could both support the validity of the system and increase understanding of how assimilation evolves throughout psychotherapy. Furthermore, by having an instrument to assess assimilation during the process of therapy, this understanding could be more easily translated into practice.

\section{Method}

\section{Participants}

Eighteen clients with depression were invited to participate, of which nine were included in this study. The remaining clients were excluded for the following reasons: two declined to participate, two were diagnosed with personality disorders, three were early dropouts (i.e. the clients dropped out before the third session, and therefore, their progress could not be attributed to therapy), and the remaining two for other reasons (i.e. one changed therapist in the second session and the other because the duration of the psychotherapy extended significantly beyond the period of data gathering). All participants were recruited from a psychology service at a psychiatric hospital in Portugal.

The clients were not required to meet any diagnostic criteria, but they were required to have a minimum Beck Depression Inventory (BDI) score of 10 indicating "mild 
depression" (Beck, Ward, Mendelson, Mock, \& Erbaugh, 1961). Three exclusion criteria were established: psychotic syndromes, personality disorders, and cognitive deficits. Of the nine cases that were included in the study, seven were female, and the average age was 40.1 years $(\mathrm{SD}=14.12)$. Most clients had either secondary education $(3 ; 33 \%)$ or licenciatura which is a five-year BA $(3 ; 33 \%)$.

The clinical cases were of low severity as demonstrated by the following three observations: four had diagnoses of sub-clinical depression (i.e. depression that did not meet diagnostic criteria), five had no significant concurrent anxiety, and six were not taking medication. This observation is also supported by the low results of the BDI (Beck et al., 1961). The mean results of the BDI are at the moderate depression level $(M=22.6, \mathrm{SD}=10.06)$.

Eleven therapists were invited and three accepted to participate. These therapists came from different theoretical orientations. Of the nine cases included in this study five were psychodynamic psychotherapies (i.e. B01, B03, B04, B05, and B09), two were systemic or family therapies (i.e. B02 and B07), and two were integrative or eclectic (i.e. B06 and B08). All therapists were female with an average age of 38.7 $(\mathrm{SD}=12.01)$. All therapists had completed their training as psychotherapists and had at least three years of practice.

\section{Instruments}

Client self-report questionnaires

Three self-report measures were used in this study.

The Beck Depression Inventory. The BDI (Beck et al., 1961) was used to assess the severity of depressive symptoms. The BDI is a 21 -item inventory that presents forced choices between several descriptions of symptoms of depression with an intensity range from zero to three. The BDI yields summary scores that range from 0 to 63 with higher scores representing greater severity of depression. The psychometric properties of the BDI have been well documented (Beck, Steer, \& Carbin, 1988). The average alpha coefficient for this measure in a psychiatric sample has been observed to be .86 . This study used a Portuguese version of this instrument (Vaz Serra \& Abreu, 1973). In the present study, the BDI presented a Cronbach's alpha of .92 .

The Brief Symptom Inventory. The Brief Symptom Inventory (BSI) (Derogatis, 1993) is a general measure of psychopathology. It is the short version of the Symptom Checklist (SCL-90; Derogatis, 1975). The BSI is a self-report inventory with 53 items that are rated on a five-point Likert scale that measures the frequency of symptoms. The BSI produces partial scores for particular diagnostic groups. In the present research, however, only the Global Severity Index was used which is a global score of symptom severity. This score is an average of the individual scores of all the items of this inventory and it ranges from zero to four, with higher scores reflecting higher severity of symptoms. Both the American version (Derogatis, 1993) and the Portuguese version (Canavarro, 1999) have been extensively researched. For example, Canavarro (1999) found internal consistency scores ranging from .62 to .79 for the different scales and the test retest reliability was .79. In the present study, the alpha reached .92 . 
The Psychological Well-Being Scale. The Psychological Well-Being Scale (PWBS) (Ryff \& Keyes, 1995) was used to assess psychological well-being. This scale follows Ryff's conceptualization of happiness and well-being (e.g. Ryff, 1989). The PWBS is a scale with 18 items that are rated on six-point Likert scales (ranging from 1 to 6). Higher scores in this instrument suggest higher levels of psychological well-being. The Portuguese adaptation was done by Novo and collaborators (Novo, Silva, \& Peralta, 1997). The PWBS has shown good psychometric properties. Lima and Novo (2004) obtained in a clinical sample an alpha of .86 and the average for the population was $63.8(\mathrm{SD}=16.4)$. In the present study, we obtained a Cronbach's alpha of .88 .

\section{Interview with the therapist}

A semi-structured interview was created to assess the perspectives of the therapists regarding client change. This interview was done at the end of the assessment period by another researcher that did not participate in further analyses. Using another researcher allowed avoiding potential influences from the view of therapist on the coding of the indices. The interview consisted of four to six questions depending on whether the therapist perceived the case as successful or unsuccessful. Table 2 presents the questions and the mains goals of each question.

\section{The system of assimilation indices}

The system of indices is a procedure for coding the speech of client and therapist in video or audio recordings of therapy sessions. The unit of analysis is the utterance, which is defined using the turn-taking criterion. In other words, a client utterance is framed within two therapist's utterances. The system of indices also allows the coding of therapist utterances and the immediate responses by the client to an intervention.

The coding is done in two phases. The first phase consists of a free-floating, nonanalytic listening of the session. In the second phase, the rater is invited to identify the indices of assimilation in each utterance. If no index is found, an absence code is available. To achieve this identification, the coding manual provides the definition of each

Table 2. Brief version of the script of the therapist interview protocol.

Question and goal

0 - Could you tell me a bit about this client [Warm-up question]

A/1 - What was the object or focus of the therapy? [Identification of central themes or processes]

$\mathrm{B} / 2$ - Do you consider that the client has changed influenced by the psychotherapy? (In the case of absence of change or circumstantial change (outside of therapy) please go to question C)

3 - How far do you think the client went, during these sessions, in the psychotherapy intervention? [Degree of change]

4 - How did change occur in psychotherapy? [Mode/Type of change]

5 - What, in the client, facilitated change? [Client processes relevant in change]

6 - What, in the client, made change harder?

$\mathrm{C}$ - If no significant change (use therapist expression) what do you think that, in the client, made the evolution of therapy harder? [Client processes relevant in change]

D - What happened when, in therapy, new meanings emerged or new changes were promoted? 
index, examples, and heuristics to facilitate coding. This information derived from the original qualitative analysis (Neto, 2011).

For example, the definition of the index "Sketch of underlying meaning" is:

This index implies that none of the [indices] above was assigned for the same segment. It should be assigned when the narrative is an attempt to understand or when it is a quasiexplanation. You should also assign this index in the case of tentative explanations. Pay close attention to expressions that reflect this process such as: "I am starting to think": or "now that I see it this way" and to expressions of doubt about an understanding.

The heuristic available for this index is: "Pay very close attention to the first time a client thinks about an issue." The examples provided in the manual are:

C: How can I explain it? It is if ... I was a different person ... the need to ... the need to act takes over and I am a different person ... a person doing an action and not thinking about it;

$\mathrm{C}$ : $\quad$ It is exhausting thinking ... always being concerned about them $\ldots$ all the time. But me ... me as a mother ... you know ... It is my duty, isn't it? So at the same time ... you know;

C: $\quad$ It was not the fact that I was young that mattered. I still have that ... innocence. It is ... I often trust people, you know? Now, as it was when I was 18.

(In all these instances there is an attempt to explain or understand and that attempt is not made as a certainty or as a theory. In a sense the new meaning can be seen as being drafted in the narrative.)

This application results in the identification of the presence of individual indices per utterance for each session. The following step is the calculation of the final score of the five dimensions. This final score is the sum of all the indices of each dimension of assimilation. This allows the transformation of a dichotomous score (i.e. presence or absence of an index in an utterance) into a continuous score per session. This continuous score per dimension reflects the influence of a particular sub-process of assimilation in a given session.

The system of indices was evaluated in a previous research (Neto, 2011) in which the system of indices was applied to 30 single psychotherapy sessions. The overall inter-rater reliabilities ranged from .69 for decentring to .88 for action. The Cronbach's alphas for each dimension of indices ranged from .70 for decentring to .80 for action. The system of indices also showed convergence with the existing coding system of assimilation: the APES (Honos-Webb, Surko, et al., 1998). The dimensions of decentring and action correlated significantly with the global score of the APES. The remaining dimensions did not associate with the final APES level showing a partial convergence.

\section{Procedure}

The therapists were asked to invite clients who were starting psychotherapy to participate in this research. The therapists were free to invite as many new clients as possible, but none invited more than three clients due to pragmatic reasons (e.g. the logistics of the recordings). 
The self-reports were applied at the beginning and the end of the assessment period. The time frame considered in this study spanned from the 1 st to the 15 th session. This interval allowed the observation of both symptom reduction and deeper changes (Barkham et al., 2006; Howard, Kopta, Krause, \& Orlinsky, 1986). If the psychotherapy ended before the 15th session, the client was still included. If the psychotherapy extended beyond the 15 th session, the client was invited to complete the self-reports, and no further sessions were recorded.

\section{Identifying dimensions of assimilation}

The first author applied the system of indices to individual sessions. The sessions were randomized using an online random number generator. The randomization of the sessions served to prevent confirmatory bias in the assignment of the indices. The randomization of the sessions was not perfect in the sense that some events or formal features hinted at the sequence of the psychotherapy. Nevertheless, most psychotherapies were varied enough to make randomization useful. The analysis was done without knowledge of the success status of each case, the results of the self-reports, and the results of the interviews with the therapists.

The decision to blind the actors in this research as fully as possible was made to ensure the triangulation of sources. The clients were unaware of stated views of their therapists when they filled out the self-reports; the therapists presented their perspectives unaware of the self-reports of their clients, and both the clients and therapists were unaware of the ratings of the researcher. The researcher had only access to the recorded sessions in a random order.

\section{Design and analysis}

This study contrasted successful with unsuccessful cases and followed a naturalistic multiple cases embedded design (Yin, 2003). This design implies the contrast of different facets of the phenomenon in multiple cases. The self-reports provided a description of change by the client, while the interview presented the therapist perspective of change. The researcher as an outside observer identified the indices of assimilation in the therapy sessions. The analysis involved the application of the system of indices and the integration of all these facets in the analysis of the cases.

\section{Classification of the clinical cases}

After all the instruments had been applied, the cases were classified according to the success of the therapy. The reliable change index (Jacobson \& Truax, 1991) was used to identify successful cases. This formula can be used to compare results before and after psychotherapy and takes into account the standard error of measurement. This means that it can be used to identify which improvements are significant or which may be due to random factors. The present study used the adaptation done by Evans, Margison, and Barkham (1998), which provides a reliable change criterion (RCC), below which there is a $5 \%$ difference attributable to error.

The RCC was calculated using the BDI, considering that the clients were being treated for depression. The criterion found for the BDI was 9.99, which means that a case 
was considered successful if the difference between pre- and post-therapy scores was above this value. In the cases in which this difference was inferior, the cases were considered non-successful.

All cases were judged according to their straightforwardness. Straightforward cases were those in which the criterion of success - a significant change in the BDI - was consistent with the expected progressions of the dimensions of assimilation in successful cases. Successful cases were expected to show two results: firstly, they should present significant trends and secondly the direction of the trends should made sense according to the phase of therapy. The expected evolutions for the dimensions were the decrease in external distress or pain or an increase in noticing, decentring, or action. Non-straightforward cases should present an inverse pattern either with respect to the existence of trends or their directions. Non-straightforward cases were analyzed further by contrasting the quantitative results of the dimensions with the qualitative perspectives on psychotherapeutic change indicated by the therapist. Excerpts from the sessions that illustrate the view of the clients on their own processes of change are also included to complement the analysis.

We will present the results for each case because no average evolution was expected. Linear regressions were performed to test the significance of the observed trends. The independent variable was the session number, and the dependent variables were each of the dimensions considered. For each case, the standardized slope $(\beta)$ is presented. A significant positive slope represents a positive linear growth of the dimension across time. The assumptions of the regression model (Pestana \& Gageiro, 2008) were tested. If the tests of any of these assumptions were significant, the model was not applicable, and the significance level was omitted.

\section{Results}

The classification of cases according to success status and straightforwardness is presented in Table 3.

Six of nine cases were straightforward in the sense that the dimensions behaved as expected. One unexpected observation was the relationship between straightforwardness and success. The proportion of successful cases was different between these groups: two out of six cases were successful in the straightforward group, and two of three cases were successful in the non-straightforward group. Although the sample size does not allow for generalization, our results raise the question of whether success is less straightforward than the lack of success.

\section{The six straightforward cases}

Four cases were considered to be straightforwardly unsuccessful. Figure 1 presents case B07 as an example of a straightforwardly unsuccessful case. In these unsuccessful cases, the early dimensions remained above the other dimensions, and the evolution of the dimensions appeared to be random.

Trend analysis supports these observations. No significant trends were found in any case. For B05, the individual dimension results were as follows: external $(\beta=.146, p=.687)$, pain $(\beta=.252, p=.482)$, noticing $(\beta=.131, p=.717)$, decentring $(\beta=-.157, p=.666)$, and action $(\beta=.203, p=.574)$. For case $\mathrm{B} 06$, the trends for the 
Table 3. Summary of the trend analyses per groups of cases.

\begin{tabular}{lll}
\hline & Straightforward cases & Non-straightforward cases \\
\hline Successful cases & B02 - Increase in action and decentring & B03 - No trends \\
& B09 - Decrease in pain & B04 - No trends \\
Unsuccessful cases & B05 - No trends & B01 - No trends (mixed) \\
& B06 - No trends & \\
& B07 - Decrease in noticing & \\
& B08 - No trends & \\
\hline
\end{tabular}

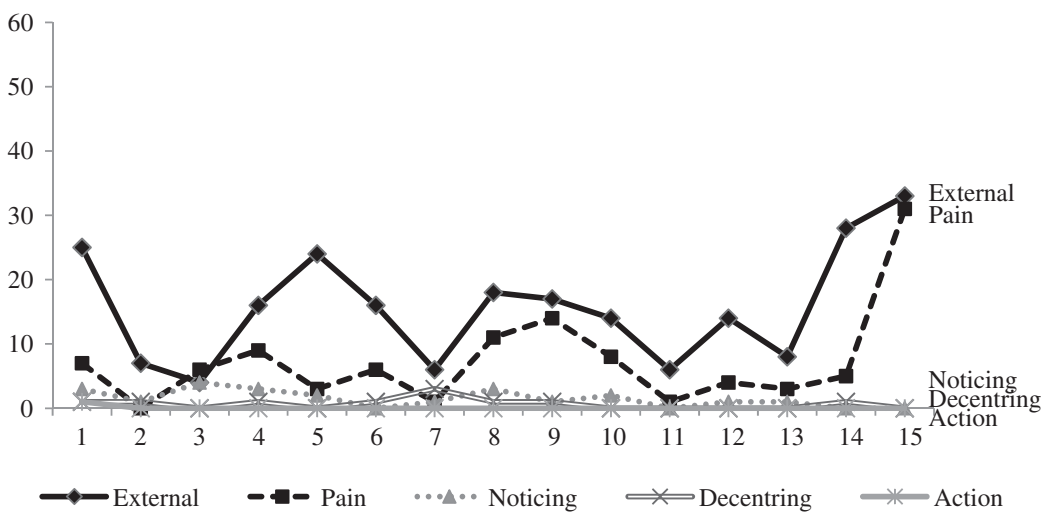

Figure 1. Frequencies of the dimensions along the therapy of B07.

dimensions were as follows: external $(\beta=.106, p=.771)$, pain $(\beta=-.033)$, noticing $(\beta=.112)$, decentring $(\beta=.011)$, and action $(\beta=.263, p=.463)$. For case $\mathrm{B} 07$, no significant trends were observed in the following dimensions: external $(\beta=.267$, $p=.335)$, pain $(\beta=-.365)$, decentring $(\beta=-.293)$, and action $(\beta=-.433)$. There was a significant trend of worsening in noticing $(\beta=-.638 ; p=.011)$. Finally, in case B08, no significant trends were observed in any dimension: external $(\beta=-.300$, $p=.432)$, pain $(\beta=-.024, \quad p=.952)$, noticing $(\beta=-.383, \quad p=.309)$, decentring $(\beta=.070, p=.858)$, and action $(\beta=-.309)$.

Two cases were considered to be straightforwardly successful. Significant trends were found in these cases. Interestingly, the dimensions with significant changes were different. In case B02, presented in Figure 2, there was a significant increase in decentring and action, while in case B09, there was a decrease in early dimensions and only pain was significant.

These observations were confirmed by the trend analysis. Case B02 exhibited significant increases in decentring $(\beta=.573, p=.026)$ and action $(\beta=.516, p=.049)$, but no significant trends were present in the remaining dimensions (external $(\beta=.056$ ), pain $(\beta=.367, p=.178)$, and noticing $(\beta=.058))$. Case B09 exhibited a significant linear trend for pain $(\beta=-.579, p=.030)$, but no trends were present in the other dimensions (external $(\beta=-.788)$, noticing $(\beta=-.458)$, decentring $(\beta=-.450)$, and action $(\beta=.176$, $p=.547))$. 


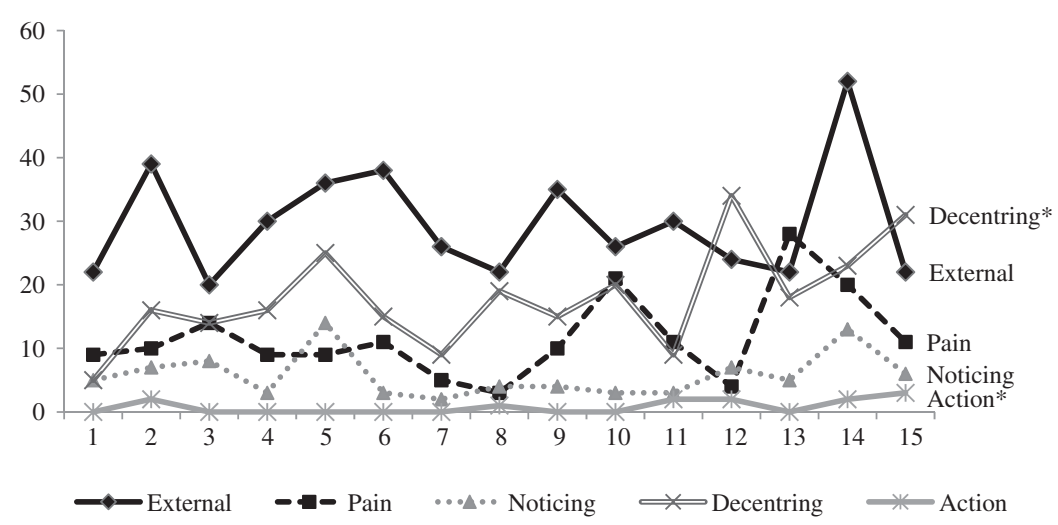

Figure 2. Frequencies of the dimensions along the therapy of B02. Dimensions with significant trends, at $p<.05$, are signaled $(*)$.

\section{The three non-straightforward cases}

In the remaining cases, there were no matches between BDI evolution and the dimensions of assimilation. In two cases, the BDI showed improvements and the dimensions of assimilation behaved like no change had occurred in another depression showed no significant evolution, but the dimensions suggested change. These cases were analyzed further to observe whether they invalidated the system of indices or whether change itself was not straightforward.

\section{Case B04}

This client was a young man in his early 20 s who came to therapy to address panic attacks. This rapidly became irrelevant, as though it was a pretext to seek help, and the focus was rapidly shifted to relationship and identity issues. These issues were visible in his professional and interpersonal life. The main problems that were addressed were procrastination, difficulties in making decisions, and conflicts with his mother that were related to family history. These issues were elaborated as the desire to be successful and appreciated, and the fear of being a failure. At the end of the psychotherapy, the client exhibited a change in BDI scores but not in the other instruments.

The dimensions of assimilation showed no change (external $(\beta=-.275, p=.386$ ), pain $(\beta=.152, p=.636)$, noticing $(\beta=-.426, p=.167)$, and decentring $(\beta=-.027))$. Therefore, the question that emerged from this discrepancy was whether the change observed in the BDI scores corresponded to changes achieved in or due to psychotherapy, or whether these changes were better explained by other factors.

This therapy was time-limited because the therapist left the institution after a few months. This limit led the therapist and client to agree goals attainable within that time frame. As the case proved to be more complex, the therapist and client did not achieve the proposed goals. The therapeutic work on the initial goals led to an increased pressure to change that was perceived by the therapist as a lack of focus on the part of the client. Change was described only as gaining insight. 
Interview with the therapist:

T: $\quad$ Because he was in circles; he jumped from issue to issue and he wouldn't stay on a theme. And when I mentioned that, he understood what he was doing and was more conscious. Although he kept jumping till the end of therapy (...) Regarding change, I think [that it happened]. He had some conscience, when we started the therapy that blaming others didn't make much sense. We started thinking about the meanings of not making choices and the impasses that he was experiencing. I think he clarified some meanings. And I also think that this was the beginning of what could be a longer psychotherapy process - which I strongly recommended because there were a lot of things left to work on.

On the client side, the change was also perceived as an insight that was described without specifying new contents or alternatives. Furthermore, he also considered the change as partial and his speech was somewhat hesitant.

Transcript of session $11\left(47^{\prime} 27^{\prime \prime}\right)$ :

C: $\quad$ I think that I realized some things that I already suspected. But ... I didn't want to think, I didn't want to know. But deep down, deep, deep down, I ended up ... finding those answers for myself. But I guess ... the fact that I realize that ... which I do unconsciously ... Now I don't know ... what can I do with ... I became aware of things. I have been becoming aware of some things. Now with those things ... because I don't know what to do with them. It is good to ... it is a starting point to be ... aware of them. Now I have to ... work them through. It has to be me that ... I don't know how to do that. It isn't ... I'm not going to be here waiting it to ... to go away. [Change in state/behavior; Do it unconsciously; States a new awareness; Incapacity to assign meaning]. ${ }^{1}$

At the end of the therapy, the therapist tried to refer the client to another therapist. The client refused and stated that he did not want to retell his story. Change in the client was equated to the clarification of meaning and seen as partial by both the therapist and the client.

\section{Case B01}

B01 was a young woman who initiated therapy after a period of great suffering. This period started when her mother went through and survived a potentially fatal disease. During this process, she supported her mother. After the recovery of her mother, the client discovered a tumor in herself. The tumor was eventually found to be benign, but this period was experienced as significantly difficult.

The client decided to initiate therapy after having dealt with the problem pragmatically but not emotionally. One factor that contributed to this action-oriented coping was that she was in the final year of her degree that included an internship that was an important goal for her.

Like the remaining self-reports, the BDI showed no change and the indices showed no significant linear trends (external $(\beta=-.038, p=.894)$, pain $(\beta=.324)$, noticing $(\beta=-.118)$, decentring $(\beta=.270)$, and action $(\beta=-.457, p=.087)$ ). These results could have allowed for the classification of this case as straightforwardly unsuccessful. However, this case was classified as non-straightforward because the indices seemed to show a clear non-linear V-shaped evolution. In other words, the dimensions showed progression but only after the midpoint of therapy (Figure 3). 
This case was considered an ongoing case at the 15 th session because therapy continued for longer than the recorded period. The case was initially influenced by the fact that the client was still in her internship and she feared being emotionally overwhelmed. The client emphasized the importance of maintaining regular functioning, which meant that therapy could not promote change that was activating. In the middle of therapy, the client successfully finished her internship. After that time, she was finally able to begin working more freely. The ongoing character of her therapy was discussed in the interview with the therapist.

Interview with the therapist:

T: $\quad$ Clearly [she has changed]. She hasn't ended therapy, and we are more than halfway through the therapeutic process, but she says that she is now much more able to be with herself and with others and that the world is no longer threatening. This is something she will currently say, and she already feels at peace with the person she is. Of course, there are still some aspects of immaturity, but she needs time to deal with those aspects. This growth won't happen in therapy.

The client also reflected on the strong impact that therapy had on her, and she described her therapy as an ongoing process, even at session 12 . Nevertheless, the metaphor that she found to assign meaning to her emotion was positive and constructive. Her emotion was seen as painful but purposeful.

\section{Transcript of session $12\left(38^{\prime} 07^{\prime \prime}\right)$ :}

\begin{tabular}{|c|c|}
\hline & I'll see you next week? [Facilitate clarification] \\
\hline C: & $\begin{array}{l}\text { Hum hum. This is just like physiotherapy, while I'm still warm ... it's painless. } \\
\text { But after that ... tomorrow everything is going to hurt all over. [Overwhelming } \\
\text { emotions; Creation of a metaphor] }\end{array}$ \\
\hline T & What will hurt tomorrow? [Explore meanings] \\
\hline & $\begin{array}{l}\text { No, it's like physiotherapy .... when I used to go there she ... [Creation of a met- } \\
\text { aphor] }\end{array}$ \\
\hline & $\begin{array}{l}\text { (Overlapping) What will hurt tomorrow? I understood what you meant. What will } \\
\text { hurt tomorrow? [Explore meanings] }\end{array}$ \\
\hline & $\begin{array}{l}\text { I always get a bit ... my heads gets a bit } \ldots \text { confused. It keeps } \ldots \text { it, my head, } \\
\text { keeps thinking about things. [Emotion stated by symptom; I am lost/confusion; } \\
\text { External meaning] }\end{array}$ \\
\hline & And ... isn't that our aim here? [Suggestion of meaning] \\
\hline & $\begin{array}{l}\text { Yeah, but it's just like physiotherapy, it hurts! [Partial agreement; Creation of a } \\
\text { metaphor] }\end{array}$ \\
\hline
\end{tabular}

Given the reports of both the therapist and the client at the time of the last assessment, the therapy was considered ongoing and to be progressing successfully. The trends in the dimensions support this, when considered from the midpoint of therapy onwards. Perhaps the changes in symptoms would have reached significance if the assessment had taken place a few sessions later. Alternatively, if the psychotherapy had started after the internship, perhaps it may have progressed during the time frame of this study.

\section{Case B03}

Case B03 was a woman in her late 20s who had recently been married and lived with her husband. Her life was deeply disturbed by the news that she had a chronic disease. 


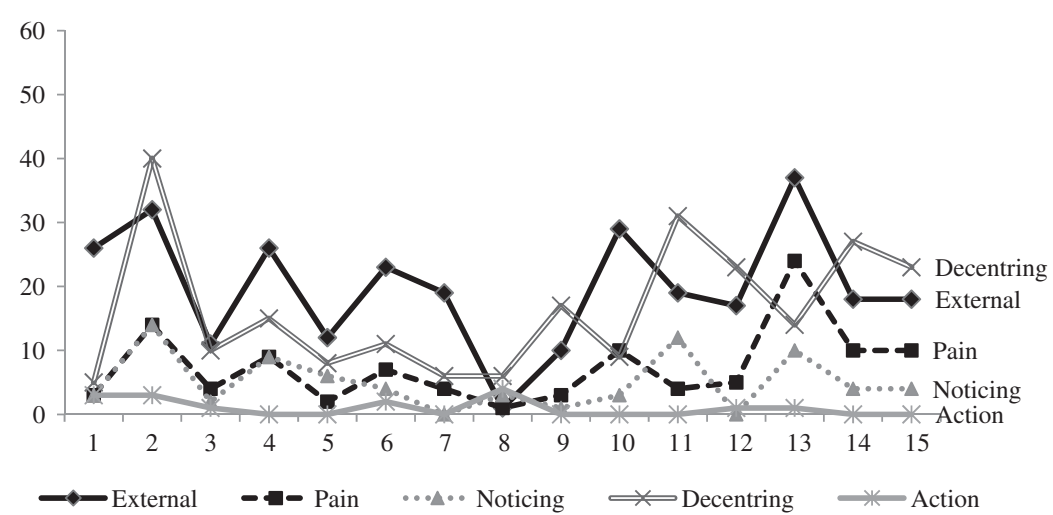

Figure 3. Frequencies of the dimensions along the therapy of B01.

The psychotherapy was particularly brief (i.e. eight sessions), and the client seemed to show a marked improvement. This rapid progress seemed to be attributable to the psychological resources of the client and the fact that the therapy was focused on adjusting to the disease.

In this case, the BDI changed significantly, but this change was not accompanied by changes in the remaining self-reports. However, no linear trends were found in the dimensions of assimilation (external $(\beta=-.234, p=.577)$, pain $(\beta=-.110, p=.795)$, noticing $(\beta=-.225, p=.592)$, decentring $(\beta=-.187)$, and action $(\beta=-.470))$.

The therapy was focused on adapting to the illness and the consequent lifestyle changes. This perspective of change was equated to adjustment and was present both in the therapist and the client. The therapist believed that the ultimate underlying issues were not severe enough to require therapy. Furthermore, the goal and object of the intervention were centered on adapting to the illness.

Interview with the therapist:

T: $\quad$ This client was discharged. The integration of the ILLNESS ${ }^{2}$ was a quick process. It was easy to uncover the roots of the problem and help her integrate the disease without it becoming her entire identity and taking over her life and the numerous daily activities she initially considered lost. Additionally, she ended up going through a brief therapeutic process that had a sharp focus on the questions related to change. In the end, she perceived this process as having been beneficial.

The client related her reaction to the disease to personal characteristics. However, she did this in a vague way that was still centered in the disease. Nevertheless, she described her change as positive and mentioned that she was able to be much more relaxed about the changes in her life.

Transcript of session $8\left(3^{\prime 2} 20^{\prime \prime}\right)$ :

C: It has. It has. Well, there are always those little things, but it has, it's overcome. And I think it's not only the ILLNESS situation ... because ... in the beginning what I brought was just the ILLNESS, but then I found out ... I have experienced 
this situation in the same way I've experienced other situations, more or less ... [Agrees and adds; Sketch of underlying meaning]

T: $\quad$ (Overlapping) Go on ... [T0]

$\mathrm{C}$ : $\quad$... similar. And I think that in here ... when I'm aware of something ... that doesn't mean I'll change, but I can ... I don't know how to deal with the unknown. And the beginning the ILLNESS was also challenging because I didn't know anything about it. And when I started learning a few things ... well, I can live with it. And it's also like this with that issue of being rigid with myself ... It doesn't mean I'm no longer like that, but now I'm conscious that I am this way, and so instead of breaking down or thinking ... I already realize that I act a certain way because I am like this. And I try to do it differently. In a much more relaxed way ... [Meaning underlying emotion; Identification of vulnerability (positive); Change in state/behavior; In this phase; Sketch of underlying meaning; Actions to deal with the problem; States a new awareness]

The client and therapist considered the change as an adaption to the illness. If this change is understood as an adjustment, no dramatic change in assimilation would be expected. Perhaps all that this client had to do was to change slightly to address the transformations in her life.

\section{Discussion}

This study was an application of the system of assimilation indices to longitudinal analyses of psychotherapies. The main question was whether the indices were useful in describing assimilation. This question was answered in two moments: the overall application of the indices to all cases and the deeper analysis of the non-straightforward cases. Regarding the overall application, of the nine cases, six were considered straightforward regarding the success of the cases. No significant trends, in the expected directions, were found in the unsuccessful cases, while significant trends emerged in the straightforwardly successful cases. Furthermore, all significant trends were in the anticipated direction. Earlier dimensions of assimilation (external distress and pain) tended to decrease, while later dimensions (noticing, decentring, and action) tended to increase in the successful cases.

The first question that emerged from the complete data was related with the observation that the unsuccessful cases tended to be more straightforward than successful cases. This observation may suggest that successful cases are more complex in their evolution than unsuccessful cases. Perhaps even the straightforward, successful cases were only straightforward because they were ongoing, while all of the non-straightforward successful cases were completed therapies. Perhaps if straightforward successful cases were followed further, their progression would cease to be linear. Another interesting observation is that none of the successful cases showed similar change processes. Even the straightforward successful cases did not show similar evolutions. One case showed significant decrease in pain and decentring, while the other others showed an increase in decentring and action. In other words, the indices are sensitive enough to describe what can be seen as different pathways for change. Together, these observations suggest that the indices are not only useful in broadly classifying cases but that they are sensitive to the complexities of psychotherapy.

The second argument for the validity of the system of indices comes from the deeper analyses of the non-straightforward cases. To understand the discrepancies between 
the indices and outcomes, the dimensions were contrasted with the perspectives of the therapists and clients about the therapy. In case B04, despite progress in the BDI scores, the dimensions suggested no internal changes, and the therapist and client believed that change was incomplete and based on insight alone. In case B01, the dimensions showed a positive trend from the midpoint of therapy onwards; the therapist described an ongoing but successful change process, and the perspective of the client was consistent with this. Client B03 was considered a successful case but one in which the dimensions suggested only minor changes. This finding was consonant with the views of the therapist and client that the psychotherapy was focused on the disease and change was equated with adjustment.

The indices may also be informative to the understanding of assimilation in a number of ways. First, assimilation was not shown to be linear. Assimilation has progressions, regressions, and stable periods. Even when assimilation does not appear to be happening, there are fluctuations. These fluctuations can be due to several factors. External circumstances may influence the emotional reaction to issues and the therapeutic relationship may foster or difficult the elaboration of meanings by the client. All these factors may hinder assimilation or provide windows of opportunity for successful intervention.

A second observation about assimilation is that at any given moment, all of the dimensions, from external to action, are present. All these dimensions play roles, and change in psychotherapy may consist of changes in proportion as much as increases in frequency. The roles that each dimension plays throughout the course of therapy are not known and will be addressed in future research. Finally, the relationship between assimilation and outcome is not linear. Assimilation and outcome exhibited some correspondence (i.e. the number of straightforward cases), but the relationship is not absolute. It may be that assimilation always eventually leads to significant reductions in depression. However, not all significant reductions are attributable to assimilation, and not all changes in this process lead to symptom reduction.

\section{Limitations}

This research has a number of limitations. This study adopts a naturalistic multiple cases design, which limits the generalization of the observed patterns. As single-case designs, it can only inform about what can happen and not how often does it happen (Yin, 2003). Furthermore, the observed patterns may have been influenced by particular contextual aspects which may not occur in other practice contexts. Another limitation comes from the coding being made by the first author and the lack of reliability check for this application. This means that the coding may have been influenced by the perspective of the researcher. In qualitative methods, this is not in itself a problem, considering that all analyses are considered to be perspectives. Nevertheless, this option is a limitation given that the manual is also inherently quantitative. This choice was considered acceptable, considering the goal of qualitatively embed indices. Furthermore, care was taken both to minimize bias and to avoid drawing conclusions from minor trends or variations. Finally, there was a concern to ensure that the different sources remained blind and uninfluenced by the remaining sources. This allowed the triangulation of sources that in most cases revealed a convergence and in those that no such convergence was found, the deeper analyses highlighted the diversity of assimilation development. 
Another limitation is that only linear trends were considered. The analysis was limited in this way because no prior research had been performed on the progression of assimilation indices. Finally, this research raises a number of questions that were not considered here due to the conservative stance of the conclusions; these questions include the relationships between dimensions, the impacts dimensions with low frequency of occurrence, like noticing, and the significance of individual indices.

\section{Clinical implications}

This research was designed specifically for clinical applicability. Considering the observations made about the successful cases, therapists can pay attention to indices that denote decentring and action. These indices reflect the creation and elaboration of meanings and the transformation of these meanings into action. Successful cases also exhibit overall reductions in pain and external distress. Clients may relinquish external explanations for their problems or expressions of pain. If therapists listen to the details of the speech of their clients, they can gain insight into the assimilation processes of their clients, which may contribute to the success of the interventions.

If the therapist of client B04 had attended to the lack of progression of assimilation she may have shifted focus earlier on, given the lack of evolution in the dimensions. By attending to the decrease in decentring, the therapist of the client B01 could have focused on the first half of the therapy in coping strategies that would facilitate the integration on the internship while saving for the second half of the therapy all the interventions that were associated with the elaboration of the illness period of her and her mother that would increase arousal. The therapist of client B03 could have seen the promising results of the therapy early on in the progression of the dimensions. These observations could be done in a moment-by-moment basis by listening to the utterances of clients.

If therapists pay attention to these indices, they can tailor intervention accordingly, optimizing intervention. A particular technique or relationship stance may be used in the proper timing leading the clients in their process of change. If the indices hint that the therapy is going wrong, the therapist can change strategy or seek supervision.

\section{Funding}

This paper was supported by a doctoral grant from the Fundação para a Ciência e Tecnologia [grant number SFRH/BD/36831/2007] to David Dias Neto.

\section{Notes}

1. The indices for each utterance are displayed in italics.

2. The name of the illness was omitted due to confidentiality concerns.

\section{Notes on contributors}

David Dias Neto completed a joint doctoral degree at the University of Lisbon \& University of Sheffield. He was trained as a psychotherapist by the Associação Portuguesa de Terapias Comportamental e Cognitiva (APTCC). Currently, he is a member of the board of directors of the Ordem dos Psicólogos Portugueses, the professional psychologists' board of Portugal. 
Telmo Mourinho Baptista is a professor of psychology and psychotherapy at the University of Lisbon, Portugal. He is the vice president of the Associação Portuguesa de Terapias Comportamental e Cognitiva (APTCC). From April 2010, he became the chairman of the Ordem dos Psicologos Portugueses and he is also the current president of Federación Iberoamericana de Asociaciones de Psicología (FIAP).

Kim Dent-Brown is a research fellow in the Centre for Psychological Services Research at the University of Sheffield. He trained as a dramatherapist and as a cognitive analytic therapy (CAT) practitioner, and also works in the National Health Service in Hull, UK, as a lead therapist in the Department of Psychological Medicine, Humber NHS Foundation Trust.

\section{References}

Barkham, M., Connell, J., Stiles, W. B., Miles, J. N. V., Margison, F., Evans, C., \& Mellor-Clark, J. (2006). Dose-effect relations and responsive regulation of treatment duration: The good enough level. Journal of Consulting and Clinical Psychology, 74, 160-167. doi:10.1037/ 0022-006X.74.1.160

Beck, A. T., Steer, R. A., \& Carbin, M. G. (1988). Psychometric properties of the Beck Depression Inventory: Twenty-five years of evaluation. Clinical Psychology Review, 8, 77-100. doi:10.1016/0272-7358(88)90050-5

Beck, A. T., Ward, C. H., Mendelson, M. L., Mock, J. E., \& Erbaugh, J. K. (1961). An inventory for measuring depression. Archives of General Psychiatry, 4, 561-571.

Bryman, A. (2004). Social research methods. Oxford: University Press.

Canavarro, M. C. (1999). Inventário de sintomas psicopatológicos (BSI) [An inventory of symptom (BSI)]. In M. R. Simões, M. M. Gonçalves, \& L. S. Almeida (Eds.), Testes e provas psicológicas em Portugal [Tests and psychological instruments in Portugal] (pp. 95-109). Braga: APPORT/SHO.

Derogatis, L. R. (1975). Symptom Checklist-90-Revised (SCL-90-R). Minneapolis, MN: NCS Assessments.

Derogatis, L. R. (1993). Brief Symptom Inventory: Administration, scoring, and procedures manual. Minneapolis, MN: National Computer Systems.

Detert, N., Llewelyn, S., Hardy, G., Barkham, M., \& Stiles, W. B. (2006). Assimilation in good- and poor-outcome cases of very brief psychotherapy for mild depression: An initial comparison. Psychotherapy Research, 16, 393-407. doi:10.1080/10503300500294728

Evans, C., Margison, F., \& Barkham, M. (1998). The contribution of reliable and clinically significant change methods to evidence-based mental health. Evidence-based Mental Health, 1, 70-72. doi:10.1136/ebmh.1.3.70

Gabalda, I. C. (2005). A micro-analysis of the assimilation process in the linguistic therapy of evaluation. Counselling Psychology Quarterly, 18, 133-148. doi:10.1080/09515070500136744

Greenberg, L. S. (2002). Emotion-focused therapy: Coaching clients to work through their feelings. Washington, DC: American Psychological Association.

Honos-Webb, L., Lani, J. A., \& Stiles, W. B. (1999). Discovering markers of assimilation stages: The fear-of-losing-control marker. Journal of Clinical Psychology, 55, 1441-1452. doi:10.1002/(SICI)1097-4679(199912)55:12<1441:AID-JCLP3>3.0.CO;2-K

Honos-Webb, L., Stiles, W., Greenberg, L., \& Goldman, R. (1998). Assimilation analysis of process-experiential psychotherapy: A comparison of two cases. Psychotherapy Research, 8, 264-286. doi:10.1093/ptr/8.3.264

Honos-Webb, L., Surko, M., \& Stiles, W. B. (1998). Manual for rating assimilation in psychotherapy. Unpublished manual. University of Miami, Miami, FL. 
Honos-Webb, L., Surko, M., Stiles, W. B., \& Greenberg, L. S. (1999). Assimilation of voices in psychotherapy: The case of Jan. Journal of Counseling Psychology, 46, 448-460. doi:10.1037//0022-0167.46.4.448

Howard, K. I., Kopta, S. M., Krause, M. S., \& Orlinsky, D. E. (1986). The dose-effect relationship in psychotherapy. American Psychologist, 41, 159-164. doi:10.1037/0003-066X.41.2.159

Jacobson, N. S., \& Truax, P. (1991). Clinical significance: A statistical approach to defining meaningful change in psychotherapy research. Journal of Consulting and Clinical Psychology, 59, 12-19. doi:10.1037//0022-006X.59.1.12

Lima, L., \& Novo, R. F. (2004). Estudo comparativo dos niveis de bem-estar psicológico nos residentes de diversas zonas industriais [Comparative study of the levels of psychological wellbeing in the residents of multiple industrial areas]. Unpublished report. CIS, Lisboa, Portugal.

Neto, D. D. (2011). Listening to elaboration in psychotherapy: The understanding of assimilation using narrative indices (Doctoral dissertation). University of Lisbon and University of Sheffield. Retrieved from http://etheses.whiterose.ac.uk/2115/2/Dias_Neto\%2C_David_M.pdf

Neto, D. D., \& Baptista, T. M. (2010). Does language mirror the elaboration of trauma? Identification of assimilation indices in narratives of patients with posttraumatic stress disorder. World Journal of Psychotherapy, 3, 186-195.

Neto, D. D., Baptista, T. M., \& Dent-Brown, K. (2011). Assimilation and meaning construction in psychotherapy. International Journal of Psychotherapy, 15, 25-37.

Novo, R. F., Silva, M. E. D., \& Peralta, E. (1997). Escalas de BEP: Versão reduzida [PWB scale: Short version]. Lisboa: Faculdade de Psicologia e Ciências da Educação da Universidade de Lisboa.

Osatuke, K., Humphreys, C. L., Glick, M. J., Graff-Reed, R. L., Mack, L. T. M., \& Stiles, W. B. (2005). Vocal manifestations of internal multiplicity: Mary's voices. Psychology and Psychotherapy: Theory, Research and Practice, 78, 21-44. doi:10.1348/147608304X22364

Pennebaker, J. W., Mehl, M. R., \& Niederhoffer, K. G. (2003). Psychological aspects of natural language use: Our words, our selves. Annual Review of Psychology, 54, 547-577. doi:10.1146/annurev.psych.54.101601.145041

Pestana, M. H., \& Gageiro, J. N. (2008). Análise de dados para as ciências sociais: A complementaridade do SPSS [Data analysis for the social sciences: The complementarity of the SPSS]. Lisboa: Sílabo.

Piaget, J., \& Inhelder, B. (1969). The psychology of the child. New York, NY: Basic Books.

Rudkin, A., Llewelyn, S., Hardy, G., Stiles, W. B., \& Barkham, M. (2007). Therapist and client processes affecting assimilation and outcome in brief psychotherapy. Psychotherapy Research, 17, 613-621. doi:10.1080/10503300701216298

Ryff, C. D. (1989). Happiness is everything, or is it? Explorations on the meaning of psychological well-being. Journal of Personality and Social Psychology, 57, 1069-1081. doi:10.1037// 0022-3514.57.6.1069

Ryff, C. D., \& Keyes, C. L. (1995). The structure of psychological well-being revisited. Journal of Personality and Social Psychology, 69, 719-727. doi:10.1037//0022-3514.69.4.719

Stiles, W. B. (2001). Assimilation of problematic experiences. Psychotherapy: Theory, Research, Practice Training, 38, 462-465. doi:10.1037/0033-3204.38.4.462

Stiles, W. B., Elliott, R., Llewelyn, S. P., Firth-Cozens, J. A., Margison, F. R., Shapiro, D. A., \& Hardy, G. (1990). Assimilation of problematic experiences by clients in psychotherapy. Psychotherapy: Theory, Research, Practice Training, 27, 411-420. doi:10.1037/0033-3204.27.3.411

Strauss, A. L., \& Corbin, J. M. (1998). Basics of qualitative research: Techniques and procedures for developing grounded theory. London: Sage.

Vaz Serra, A. S., \& Abreu, J. P. (1973). Aferição ao dos quadros clínicos depressivos: Ensaio de aplicação do "Inventário Depressivo de Beck" a uma amostra portuguesa de doentes deprimidos [Measurement of depression: Application of the Beck Depression Inventory to a Portuguese sample of depressed patients]. Coimbra Médica, 20, 623-644.

Yin, R. K. (2003). Case study research: Design and methods. Thousand Oaks, CA: Sage. 